\title{
Modelos de Assistência Médico-Social Para os Trabalhadores na Colômbia, o Caso da Empresa Minera El Zancudo, 1865-1948 Oscar Gallo
}

\section{RESUMO}

GALLO, O. Modelos de assistência médico-social para os trabalhadores na Colômbia, o caso da Empresa Minera El Zancudo, 1865-1948. A Empresa Minera El Zancudo (EMZ) se destacou na paisagem industrial colombiana pelo nível de complexidade da produção, a estratégia de gestão inovadora e as formas de organização do trabalho. Nesse cenário complexo, é possível identificar aspectos relacionados a doenças ocupacionais, acidentes de trabalho, higiene industrial, medicina do trabalho e legislação trabalhista. Além disso, podem-se examinar as formas de resistência dos trabalhadores, responsabilidades, tensões e negociações para o controle de riscos, doenças e acidentes. O objetivo deste artigo é analisar o processo histórico de formação de vários modelos de assistência médico-social e proteção das vidas dos trabalhadores, em uma população associada com a EMZ. Ao analisar as particularidades desses modelos de assistência médica e social para trabalhadores mineiros, é possível ver como estes se enquadram no horizonte mais amplo de transformações dos paradigmas produtivos e de mudanças nas formas de assistência e previdência social.

Palavras-chave: assistência médico-social; doenças ocupacionais; mineração (Colômbia).

\section{ABSTRACT}

GALLO, O. Social-medical assistance models for workers in Colombia, the case of El Zancudo Mineira Company, 1865-1948. The El Zancudo Mineira Company (EMZ) stood out in the industrial Colombian landscape by the level of production complexity, management strategy and innovative forms of work organization. In this complex scenario, it is possible to identify aspects of occupational diseases, work accidents, industrial hygiene, occupational medicine and labor legislation. Moreover, one can examine the forms of worker resistance, responsibilities, tensions and negotiations for risk, diseases and accidents control. The goal of this article is to analyze the historical process of the formation of various models of social and medical assistance and protection of the workers lives in a population associated with the EMZ. While analyzing the peculiarities of these medical and social aid models for mining workers, it is possible to see how these ones fit in the most spacious horizon of transformations of the productive paradigms and changes in the forms of social security and welfare.

Key words: medical-social assistance; occupational diseases; mining (Colombia)

\section{INTRODUÇÃO}

A EMZ é um dos fenômenos econômicos e empresariais mais destacados da história de Colômbia (MOLINA, 2003; MAYOR MORA, 1997). Sua operação entre 1848 e 1948 abrange um século e, portanto, permite ler transformações importantes na história do trabalho do país. Várias 
características sustentam esse destaque. Em primeiro lugar, os níveis de produção intensiva vinculados a uma complexa rede de produção, organização e divisão do trabalho, aspecto que levou os engenheiros da época a afirmar: "El nombre de esta empresa representa la mayor perfeción alcanzada en el país en el arte de beneficiar menas" (PEREIRA GAMBA, 1901, p. 100). Em segundo lugar, sobressai a consolidação de uma mão-de-obra qualificada, com melhores condições de trabalho e incentivos sociais. Em terceiro lugar, assistência médico-social para os mineiros e suas famílias, com reconhecimento de algumas doenças ocupacionais e acidentes de trabalho (GALLO, 2010).

Este artigo analisa os diferentes modelos de assistência médico-social que funcionaram na EMZ entre 1865 e 1948. Trata das condições locais de seu surgimento e configuração, mas também se pergunta sobre a forma como esses modelos se incorporaram e se sustentaram dentro das trajetórias nacionais marcadas por um conjunto de reformas sociais e novos paradigmas produtivos.

Na primeira parte, analisa-se o modelo de assistência médica baseado na caridade e na beneficência privada ou paternalismo industrial. Na segunda, descreve-se o surgimento e o funcionamento dos modelos característicos da administração científica do trabalho. Finalmente, na terceira parte, considera-se a instauração do modelo característico da assistência pública, a previdência social e os direitos em saúde.

\section{Caridade, beneficência ou assistência médica privada, 1865-1898}

Desde sua criação, em 1848, a EMZ se destacou no âmbito colombiano por suas lideranças e avanços produtivos. Sua história administrativa pode se dividir em gerência ou administração empírica (1848-1862); administração Reinhald Paschke (1863-1865); administração moderna ou empírico-racional (1865-1898); administração científica (1897-1927); administração Robert Bosford (1928-1930); arrendatário El Zancudo de Bernardo Mora, Jesús Escovar A. \& Cia. (1930-1948). Desde 1865, os historiadores identificam grandes níveis de pioneirismo e inovação administrativa graças aos contínuos desafios produtivos. Porém, a faceta produtiva não foi o único desafio das administrações empírico-racionais e a posterior administração científica. Os administradores e engenheiros tiveram que organizar uma indústria cuja média anual era superior a 1000 trabalhadores.

Num cenário industrial dessa magnitude, cabe pensar que um dos aspectos significativos era a saúde dos trabalhadores. No entanto, as fontes encontradas sugerem que entre 1865 e o final do século XIX, o tipo de relação da indústria com a saúde do trabalhador estava mais próximo de uma representação social e cultural do trabalhador pobre, que eventualmente poderia ficar doente e necessitar de cuidados médicos. Nesse período, saúde, doença e corpo do trabalhador não apareciam como realidades para fazer cálculos e atribuir responsabilidades patronais. A medicina ocupava um papel secundário na estrutura de gestão da EMZ, o qual contrastava com a força do controle do alcoolismo e da vadiagem. Em detrimento da preocupação com a saúde do trabalhador ou do controle sanitário da mina, a administração empírico-racional do século XIX dirigia toda sua atenção aos vícios do trabalhador: ordem, disciplina e docilidade.

Isso não quer dizer que em todos os casos a saúde dos trabalhadores foi desconsiderada. Nas contratações de vários alemães levados à região para trabalhar na EMZ, os serviços médicos constam como requisito para a contratação de estrangeiros. Assim, em 1858, Tyrrel Moore celebrou 
um contrato por seis anos com o fundidor alemão Karl Moritz Koch ${ }^{1}$. Moritz deveria trabalhar 12 horas diárias, com dedicação exclusiva e respeitar costumes civis e religiosos, enquanto à EMZ cabia:

Pago mensual y cumplido del sueldo estipulado en Alemania; la donación de 200 francos para los preparativos del viaje, así como el adelanto de otra suma para la familia del contratado, los cuales se comprometían a satisfacer íntegramente por medio de la cesión de la cuarta parte de sus primeros sueldos mensuales, en los establecimientos de la compañía; a la asistencia médica y el pago de la mitad de su sueldo mientras tuviera enfermedad, "bien entendida que ella no haya sido por causa de descuido, ni exceso"; el pago de 400 francos, en caso que la compañía abrogase el contrato y despidiese al contratado cuando lo quisiese o estimase conveniente sin darle un preaviso con tres meses de anticipación; a proporcionar los gastos de regreso al lugar de origen, después de cumplidos los seis años de servicios, solo en el caso de que salieses durante el primer mes después de su despido (MOLINA e CASTAÑO, 1988, p. 649).

Desde cedo, no século XIX, as empresas mineiras assinavam contratos com engenheiros e técnicos metalúrgicos, comprometendo-se a garantir a assistência médica. Essa inclusão de serviços médicos respondia principalmente à dinâmica contratual entre técnicos estrangeiros e industriais colombianos. Mas o mesmo não acontecia com mineradores e operários nacionais. De acordo com os indícios, a saúde do mineiro nacional não estava entre as prioridades dos proprietários da EMZ durante segunda metade do século XIX. Em primeiro lugar, o sistema de organização de trabalho mineiro, em funcionamento desde 1879 , consistia no pagamento por extração de mineral:

En la explotación propiamente dicha, el trabajo se hace por operario a los cuales la Empresa compra la mina extraída y que no reciben de la Compañía sino la herramienta y su arreglo. La Empresa les vende la pólvora, el alumbrado, la madera de mina, etc. Y les compra los minerales [...] Los operarios se alimentan por su propia cuenta. Este modo de organización se designa con el nombre de cuarteo (PEREIRA GAMBA, 1901, p. 113).

Dessa forma, os níveis de extração mensal triplicavam. Mas para aumentar seus ganhos, os mineiros trabalhavam além de seus próprios limites, sem tomar as medidas necessárias, colocando suas vidas em perigo. Além disso, num sistema de contratação indireta deste tipo é impossível exigir a responsabilidade quanto aos acidentes, e o minerador fica responsável pelo cuidado com a sua saúde e a de sua família (1943, p. 176). ${ }^{2}$ Assim, a empresa era a única responsável pela saúde dos técnicos estrangeiros e em 1892, dos 1.224 trabalhadores da EMZ, 156 eram contratados diretamente.

Porém, é possível pensar que os mineiros pobres acabavam dependendo do modelo de assistência médica baseado na beneficência público-privada. Com efeito, a caridade estava entre as 'obrigações morais' da EMZ e com certeza foi este o motivo para que, em 1865, o médico Ricardo Escobar Ramos, sócio da EMZ, fundasse com outros membros da comunidade o Hospital de Caridade na cidade de Titiribí. A criação do hospital sugere um tipo de vínculo entre a instituição e a EMZ o qual se fazia muito mais perceptível por conta da proximidade geográfica - mais ou menos um quilômetro - entre as minas e o hospital.

Todavia, outro aspecto faz pensar num modelo de assistência médica legitimado pelas necessidades da EMZ. Entre 1865 e 1904, foi possível encontrar indícios da presença de mais de seis médicos 
na região (quando em muitas outras cidades da Colômbia, sequer havia médicos). Sem dúvida, a demanda da EMZ influenciou essa oferta de agentes de saúde. O pagamento por tratamentos médicos pode ter sido muito comum ${ }^{3}$, porém, no caso desta região mineira, a peculiaridade era o fato de todos os médicos ocuparam o cargo, oficialmente, dentro do Hospital de Caridade. Todos esses vínculos contingentes entre o hospital e a EMZ adquirem mais consistência com os testemunhos de auxílios econômicos por parte da indústria mineira para o hospital. Sobre esse tema, em 1912, o prefeito de Titiribí lembrava que o Hospital de Caridade contava sempre com a generosidade dos vizinhos, os auxílios do município e da EMZ (AHA, 1918). Em síntese, tanto os médicos presentes no município quanto o Hospital de Caridade serviram durante este período, sem contratos explícitos, aos interesses da indústria mineira.

\section{O surgimento de um modelo de assistência médico-social, 1897-1924}

Com o início das administrações científicas, o panorama da saúde dos trabalhadores começou a se transformar. Projetos como o serviço médico e o departamento sanitário acoplaram-se a um modelo amplo de solidariedade empresarial que visava a maiores resultados econômicos. $\mathrm{O}$ uso desses tipos de benefícios indiretos ou auxílios estava relacionado com a solidariedade moral. A lealdade e a disciplina eram conseguidas através de mecanismos sensíveis de pressão, já que os problemas sociais se resolviam melhor de maneira indireta. No informe anual de 1919, o engenheiro e administrador Alejandro López ${ }^{4}$ enumerava os benefícios disponíveis pela empresa aos operários: educação para os filhos, terrenos para edificação das casas, assistência médica gratuita, medicamentos baratos e auxílio-doença, pagamento antecipado em situações difíceis. Para os trabalhadores fixos, havia moradia gratuita e direito a ocupar cargos superiores, o que era o estímulo mais poderoso para o homem, de acordo com López (1919, p. 18).

Em 1917, dois anos antes do informe de López, um visitante procedente da capital do país louvava a ordem e a limpeza das casas. Da mesma forma, ressaltava a adjudicação dos terrenos para edificação e os benefícios econômicos a cada seis meses: "un premio de a \$ 5 y los de a $\$ 2,50$ a los tres obreros que más se han esmerado en conservar en buen estado sus casa, huertas y jardines” (GUTIÉRREZ, 1921). Finalmente, para atrair mão-de-obra, recorreu-se a uma inovadora mutualidade, protegida pela direção, cujo fim era poupar vinte centavos semanais por operário, para, uma vez alcançando 1 peso, melhorar a casa de um dos sócios.

Entretanto, esses benefícios indiretos não surgiam exclusivamente como parte do modelo de gestão científica. Alguns deles foram motivados pelas dificuldades para conseguir e manter os mineiros especialistas na exploração de ouro e carvão, como se pode concluir das palavras do engenheiro López: "Creo que necesitamos construir algunas habitaciones en los alrededores de la Mina para formar una colonia de mineros que no esté viajando a lãs explotaciones vecinas, pues los que tenemos viven muy dispersos y alejados del trabajo" (1915, p. 14). Às contingências produtivas, somava-se o cálculo racional do impacto das doenças na produção. Assim, Miguel María Calle, médico da EMZ de 1904 a 1912, calculava o impacto econômico da ancilostomíase:

Tratase de un individuo fuerte y sano que llega a la mina y se coloca como "carreteador"; por cada carretada de mineral recibe un centavo y en el día puede mover alrededor de 70 carretadas. Después de trabajar un mes y medio sufre candelillas y mazamorras. De 70 carretadas pasa a 30, 20, 10 sucesivamente; "alarmado y deprimido reclama los cuidados médicos y se le 
somete a un tratamiento por el timol". Los efectos son inmediatos y vuelve a su régimen de trabajo inicial'(CASTRO, 1923, p. 406).

Para Alfonso Mejía, engenheiro da EMZ, a "preguiça” dominante entre os trabalhadores era resultado desse tipo de doenças tropicais, como a ancilostomíase. Por essa razão, insistia que sua terapêutica e profilaxia fosse motivo de estudo dos engenheiros e, especialmente, dos chefes de empresas agrícolas e mineiras, nas quais se adquiria a doença mais facilmente (MEJÍA, 1918, p. 455). Em síntese, frente à falta de cuidados higiênicos por ignorância ou indolência dos empresários, Mejía julgava conveniente dispor de serviço médico ou auxílios para os operários, como acontecia na EMZ:

En cuanto al auxilio [de enfermedad], se puede establecer una especie de cooperativa entre los mismos obreros, obligándolos a dejar, en caso de quieran participar de este beneficio, un dos por ciento de jornal semanal. Con estas pequeñas cuotas se forma un fondo común que pertenece únicamente a los obreros, reservándose la Dirección la distribución de acuerdo con las necesidades del obrero y con el monto semanal de su jornal. En la Empresa Minera de Zancudo, quizá la única en Antioquia que tiene establecida esta práctica, el obrero, en caso de enfermedad, recibe un auxilio que varía entre uno y dos pesos semanales. En caso de accidente de trabajo, el auxilio sale de los fondos de la Empresa, según lo ordena la Ley (MEJÍA, 1918, p. 454).

Mejía expande a proposição e reflete sobre o papel do empresário quanto às doenças do trabalhador: "[...] toca al gobierno remediar esto, con una buena legislación obrera, pues no es corriente que el industrial dañe un hombre para que lo repare la caridad pública o la privada” (MEJÍA, 1918).

As palavras do engenheiro Mejía ou a visão do Dr. Calle resumem uma perspectiva compartida pela direção de López e pelos médicos da EMZ. A gestão científica, com suas preocupações relativas à simplificação do trabalho e à economia de movimentos em função da produção, exigia um vínculo entre médicos e engenheiros como observadores imediatos do trabalho. Com a mesma lógica, Juan de la Cruz Posada, outro representante da EMZ, apontava: "al ingeniero le incumbe disponer las condiciones del trabajo con la mira puesta, también, en la salud del personal [para] amortiguar el mal" (POSADA, 1940, p. 8385). Isso porque, para o modelo de administração científica, importava, sobretudo, um operário saudável e ambicioso. Saudável, já que o doente não era útil para o trabalho; ambicioso, porquanto dessa forma eram aplicáveis os sistemas de ganho por incentivo, os salários segundo o nível de produção e as medidas do trabalho diário no lugar da medição por unidade de tempo (MEJÍA, 1918, p. 443). Finalmente, Alejandro López destacava a facilidade de adaptação e a perseverança do pessoal integrado neste modelo que, por um lado, aumentava visivelmente os custos de funcionamento da empresa pelos inúmeros gastos com pensões por doenças e aposentadorias, mas por outro, permitia a permanência do pessoal qualificado (LÓPEZ, $1918 ; 1919$, p. 18).

Em outros termos, num contexto de economia da saúde característico da virada do século XIX e inícios do século XX, o serviço médico adquiriu um papel inusitado dentro da estrutura organizacional da EMZ. Criado possivelmente em torno de 1897, para ele foi contratado o médico Miguel Maria Calle em 1904, seu principal dinamizador até 1912. Em 1905, esse médico atendia quase 1.500 operários e famílias dispersas no extenso território que conformava as diversas seções da empresa mineira (CALLE, 1949, p. 295). Em poucos anos, de 1904 a 1912, o serviço de assistência médica da EMZ conquistou níveis de complexidade e cobertura; contudo, essa é apenas uma das 
facetas destacadas da seção da mina orientada à saúde dos trabalhadores. O serviço sofreu várias e paulatinas transformações que fizeram dele um paradigma da assistência médico-social baseada em três eixos: terapêutico, profilaxia e pesquisa.

Em relação aos avanços terapêuticos, destacam-se os tratamentos de acidentes por grisu e a terapêutica da ancilostomíase, cujos êxitos foram divulgados em revistas médicas do país (LÓPEZ, 1913a). Acima da terapêutica, sobressai o interesse dos doutores da mina pela instauração de medidas de profilaxia contra doenças como a citada ancilostomíase, assim como a tuberculose e a tricocefalose. Nesses casos, a profilaxia, baseada em trajetórias de pesquisa no terreno, resultou em ações exemplares de controle e prevenção das doenças. De fato, as diretivas da empresa, em conjunto com os médicos, apostaram em intervenções que combinavam uma prática terapêutica individual com propostas de intervenção coletiva através de campanhas educativas. Ao incluir uma visão preventiva e educativa entre suas prioridades, a indústria ganhou o reconhecimento nacional e colocou-se na vanguarda da profilaxia das ancilostomíases muito antes da chegada da fundação Rockefeller à região, entre setembro de 1922 e abril de 1923 (CASTRO, 1923).

A EMZ também levou a cabo campanhas contra a tuberculose ou tísica pulmonar (LÓPEZ, 1913b, p. 163). No entanto, o êxito nesse terreno foi muito menor que no campo das doenças parasitárias principalmente porque os médicos da época, preocupados com uma doença infecciosa (tuberculose), não conseguiram enxergar a possível causa mecânica da doença (silicose) (GALLO e MÁRQUEZ, 2011a; 2011b). As campanhas encaravam o problema da mesma forma que o faziam quando era enfrentada a tuberculose. As medidas tomadas não evitavam os seus trágicos efeitos e era necessário conceder auxílios aos atacados pela enfermidade, o que não significava evitar o "contágio" futuro. Segundo López: "todavía me parecen pocos los muchos cuidados del personal superior para contener el contagio” (1918, p. 18).

Se de 1904 a 1912 houve uma relação estreita entre a atividade do Hospital de Caridade e os serviços médicos da EMZ, a partir de 1912 consolidou-se outra dimensão de atendimento médico para os trabalhadores. A respeito deste tema, em 1915, Lopez lembrou as mudanças do Departamento Sanitário da EMZ: “[...] desde hace más de tres años se viene prestando verdadera atención al Departamento" (1915, p. 19). Com efeito, o médico de Titiribí foi transferido para imediações da mina. Em 1916, foi criado um hospital para uso exclusivo da EMZ:

En el pequeño Hospital que hubo la necesidad de abrir para atender mejor a los enfermos se trataron en los 11 meses 77 enfermos, de los cuales 36, o sea próximamente (sic) la mitad, sufrían disentería infecciosa. Me atrevo a asegurar que si no hubiera existido el Hospital, habría sido imposible luchar contra esta epidemia (LÓPEZ, 1916; 1917).

Por outro lado, o médico da empresa atendeu no hospital da mina uma média mensal de 422 pessoas, entre os meses de janeiro e novembro de 1917, isto é, um total de 4.622 pacientes, entre trabalhadores e familiares. A magnitude dos serviços foi ampliada pelo engenheiro Alejandro López num de seus informes anuais. Segundo ele, uma média de 4.500 pessoas era dependente do médico da empresa, em contraste com uma folha de pagamento de 1.000 trabalhadores. A mortalidade relativa ao pessoal da empresa e seus dependentes foi de 84 mortos em 1917, ou seja, uma taxa de 20 por 1000 anuais. A cifra de 4.500 pessoas a cargo do médico da mina representava, aproximadamente, um terço dos habitantes de Titiribí, pois, em 1917, este município tinha 13.724 habitantes. O Dr. Wenceslao Montoya registrou 6.500 pessoas, entre trabalhadores e familiares 
(MONTOYA, 1923, p. 43), que ficavam a cargo do médico, i.e., 2.000 indivíduos a mais do que os registrados por Alejandro López, para o mesmo período.

Contudo, não se pode imaginar um compromisso econômico permanentemente à frente das doenças crônicas. O modelo não estava em capacidade para compromissos de longo prazo. Por conseguinte, é possível que estivesse mais vinculado à atenção de acidentes de trabalho. Assim, em 1917, Rufino Gutierrez, observava com admiração que na EMZ funcionava um modelo de indenização por acidentes de trabalho que parecia haver inspirado a legislação nacional. Entretanto, frente às doenças ocupacionais, Calle era mais sensato: "El obrero es útil y digno de atenciones mientras con su labor ayuda a adquirir fortuna; más cuando está desvalido y enfermo, aunque sea por causa del trabajo, ya es un ser inútil y estorboso de quien es preciso desasirse" (CALLE, 1910, p. 83).

\section{Da administração científica da doença aos direitos de saúde, 1924-1948}

Em contraste com o que havia entre 1904 e 1924, quando os trabalhadores da EMZ tinham médico dedicado ao seu atendimento e serviço de hospital, o sistema se estreitou e as instalações médicas da EMZ desapareceram. Os anos seguintes foram de transição de um modelo de assistência médicosocial articulado com o sistema produtivo para um modelo centralizado de serviços médicos, quer dizer, uma assistência médica aos acidentes de trabalho que se cumpria no hospital do município, fundamentado na nascente legislação trabalhista. Disso é testemunho o informe do médico oficial, em 1930:

[...] el consultório atiende preferentemente los accidentes graves que con frecuencia se presentan que generalmente resulta en obreros pobres, tales como fracturas, luxaciones, quemaduras, son muchas las operaciones de pequeña cirugía que se practican como extracción de tumores, cuerpos extraños[...] (AMT, 1923).

Por que se deu esse trânsito do exclusivamente privado ao público-privado? Sem dúvida, as dificuldades econômicas da indústria mineira tiveram peso maior; não obstante, é impossível não citar as mudanças estruturais na política social.

Na história da Colômbia, a década de 1920 caracterizou-se pelo debate político sobre as reformas laborais concernentes a tempo de trabalho, aumento dos salários e direito dos trabalhadores à associação, enquanto na década de 1930, discutia-se sobre todos os problemas e causas da vulnerabilidade social (fome, doenças ocupacionais e profissionais, hábitat, condições de trabalho, deterioração do corpo pelo trabalho, saúde do entorno familiar) e se demandava, claramente, o direito à saúde (HERNÁNDEZ, 2002, p. 107). Embora existam diferenças nacionais, boa parte dos estados ocidentais começou a legislar em favor dos trabalhadores em torno dos anos 1910-1930. Assim, no caso da Colômbia, sobressaem: Lei no 48, de 1914, sobre a proteção da criança; Lei, $\mathrm{n}^{\circ}$ 57, de 1915, sobre acidentes de trabalho; Lei, no 12, de 1927 e Lei n. 133, de 1931, sobre acidentes e seguro coletivo; Lei n 37 , de 1921, Lei n ${ }^{\circ} 32$, de 1922 e n ${ }^{\circ} 44$, de 1929 , sobre o seguro obrigatório e coletivo de empregados; Lei no 26, de 1934, sobre horas máximas de trabalho; Lei no 149 , de 1936, sobre pessoal estrangeiro, seguro-coletivo e seguro-desemprego; Lei ${ }^{\circ} 10$, de 1934, sobre férias remuneradas e auxílio-doença, duração máxima do trabalho, descanso aos domingos; Lei n ${ }^{\circ} 53$, de 1938, de proteção à maternidade. Note-se que, de acordo com dois advogados da época, a política social na Colômbia tinha pouco peso sobre o capital, o que devia ser lido como um compromisso 
geral do Estado colombiano para proteger e estimular a indústria. Essa aceitável legislação se devia "a que entre nosotros no predomina[van] ni prospera[van] las tendencias extremas [comunismo e socialismo], a que no exist[ia] todavia el hecho económico social de la gran industria y a la falta de grandes masas obreras" (ECHEVERRI e URIBE, 1939).

Nesse contexto de transformações políticas, é muito difícil ponderar o papel dos movimentos operários no campo da saúde, mas com o estado atual das pesquisas históricas na Colômbia, há que se reconhecer que o sindicalismo coadjuvou nas reformas do campo laboral. Num sentido estrito, se durante os anos 1920 a preocupação dos sindicatos se concentrou na organização do trabalho e em estabelecer regras laborais precisas e manter o direito de associação, entre 1930 e 1950, a preocupação com a saúde dos trabalhadores alcançou seu ponto mais agudo em duas frentes: primeiro, no controle sanitário do cenário produtivo e na instauração de práticas, técnicas e normas para a prevenção dos acidentes; segundo, na normalização e estabilização da assistência médica para doenças ocupacionais e profissionais, assim como na conquista do direito à saúde (HERNÁNDEZ, 2002). Não é possível escolher uma única razão para esse trânsito do ato de beneficência aos direitos de saúde. Como já se afirmou, as contingências produtivas da mineração deflagraram o fechamento do Departamento Sanitário. Mas não foram menos determinantes as trajetórias nacionais das reformas sociais, os processos sindicais, a incorporação dos conflitos entre capital e trabalho no horizonte das convenções da OIT e, inclusive, os avanços no campo da higiene industrial e da medicina do trabalho.

Em 1940, constitui-se o Sindicato de Mineros y Baharequeros de Zancudo y de Titiribí, em conformidade com a Lei no 83 de 1931 que permitia a sindicalização. Os recém-sindicalizados tinham entre os principais desafios fomentar a poupança individual e coletiva e a ajuda moral e material entre os sócios; desenraizar os preconceitos e incompreensões que dividiam o grêmio dos mineradores, de forma que fosse possível fundir interesses de patróes e operários; capacitar os membros em diferentes especialidades; reduzir o preço dos artigos de primeira necessidade por meio de uma cooperativa de consumo (AMT, 1940a). A direção do sindicato era composta por presidente, vice-presidente, tesoureiro, secretário, vários vogais e três comissões permanentes: Hospital, Propaganda e Execução. A primeira tinha por objetivo visitar os sócios doentes, enviálos ao médico do sindicato e, caso necessário, ajudar na hospitalização. Esse atendimento podia ser feito pelo corpo médico da empresa, mas também mediante serviços médicos e medicamentos aportados pelo sindicato e sem custo para os associados. Com efeito, entre suas reivindicações estava o direito à saúde representado na exigência de assistência médica gratuita para os trabalhadores e suas famílias.

No mesmo ano de 1940, sob a pressão continuada do Sindicato, o regulamento interno de trabalho da EMZ condensou os avanços na política social do país. As frentes de intervenção legislativa eram referentes à organização do trabalho e à proteção da saúde do trabalhador. Com relação à organização do trabalho, foram incluídos requisitos formais para admissão, como carteira de identidade, certificado de reservista, exame médico realizado pelo médico da empresa ou certificado de sanidade. Estes últimos tinham como objetivo avaliar a aptidão para o trabalho, evitar riscos e controlar as medidas de segurança. Havia também uma clara indicação ao período probatório de 60 dias. Transcorrido esse tempo, o empregado ingressava definitivamente na empresa e, no caso de dispensa, tinha direito à prestação social.

Em relação à jornada de trabalho, segundo o Decreto executivo n 895 , de 1934 , da Oficina General de Trabajo, e a Resolução n ${ }^{\circ} 34$, de 1937, do Ministério de Indústrias y Trabajo, o trabalho eficaz para a atividade mineira consistia numa jornada de oito horas diárias e quarenta 
e oito semanais. Já para os trabalhos que não eram suscetíveis de interrupção, como nas estações de gás, ensarilhamentos, cianuração, moinhos e fornos torradores, as jornadas eram de 12 horas. Além de acatar tais disposições, a empresa contemplou um aumento superior a $25 \%$ pelo trabalho diurno extra e $50 \%$ pelo noturno extra. A limitação da jornada de oito horas era uma vitória da classe trabalhadora (Lei $n^{\circ} 37$, de 1922). O descanso dominical e os dias $1^{\circ}$ de janeiro, $1^{\circ}$ de maio, 20 de julho, 7 de agosto, 12 de outubro, 11 de novembro e 25 de dezembro como feriados (Lei $\mathrm{n}^{\circ} 35$, de 1939), assim como 15 dias de férias no ano (Lei $\mathrm{n}^{\circ}$ 10, de 1934) (AMT, 1940b) foram outras conquista da classe. Conforme a Lei ${ }^{\circ} 57$, de 1926, a cada seis dias de trabalho, operários e empregados dispunham de 24 horas de descanso e, no caso das entidades municipais, este dia era remunerado.

Os salários dos mineiros eram muito variáveis. Não havia uma escala estrita para fixá-los. Variavam de acordo com os preços dos alimentos, altos e baixos da produção e quantidade de mão-de-obra disponível. Em 1947, por conta do alto custo dos víveres, o prefeito do distrito decidiu aumentar, por decreto, o valor do salário dos trabalhadores oficiais, dos mineiros e dos sobrestantes; assim, oficiais de obra ganhavam 1 peso e 50 centavos; marceneiros, 4 pesos; mineiros, 5 pesos; sobrestantes, 7 pesos (AMT, 1947).

Com respeito à proteção da saúde para os trabalhadores, as frentes de intervenção se referiam a acidentes de trabalho, seguro-doença obrigatório e o reconhecimento de doenças ocupacionais e profissionais. Segundo o regulamento de trabalho da EMZ, era considerado acidente de trabalho "un suceso imprevisto y repentino sobrevenido por causa y ocasión del trabajo y que produce en el organismo de quien lo ejecuta una lesión o perturbación funcional permanente o pasajera, todo sin culpa del empleado u obrero". Esta definição seguia, ao pé da letra, a Lei n 57, de 1915. Entre os acidentes de trabalho, incluíam-se quatro categorias: incapacidade temporária ou lesão passageira com cura completa; incapacidade permanente parcial ou perda da capacidade definitiva de trabalho por lesão anatômica de um membro funcional, de um olho, da audição ou enfermidade traumática sem necessidade de inatividade; incapacidade permanente ou total quando, por exemplo, houvesse perturbações mentais incuráveis, perda de ambos os membros, olhos, mãos ou traumas definitivos nas vísceras abdominais ou torácicas; finalmente, a morte (COLOMBIA, 1933, p. 573). A primeira incluía um auxílio de $2 / 3$ do salário, durante o processo de recuperação total. A incapacidade permanente parcial era a diminuição definitiva da capacidade de trabalho e remunerava-se com $2 / 3$ do salário durante o tempo de recuperação. De acordo com o laudo do médico da empresa, o operário recebia indenização durante dois meses, no mínimo, e um ano, no máximo. A incapacidade permanente ou total estimava uma indenização equivalente a $2 / 3$ do salário até a que a lesão fosse curada; depois, o operário recebia da empresa o equivalente a dois anos de salário. Por último, em caso de morte, a empresa pagava aos beneficiários o valor do seguro de vida e cobria os gastos do enterro, além de $2 / 3$ do salário durante o tempo de incapacidade antes do falecimento. Em qualquer uma das categorias, a empresa era responsável pela assistência médica, cirúrgica, farmacêutica, hospitalização e alimentação.

O décimo capítulo do regulamento da mina incluiu o serviço médico e os auxílios por enfermidade. $\mathrm{O}$ apoio pecuniário era de $2 / 3$ partes do salário durante os primeiros 60 dias; a metade nos 30 dias seguintes e uma terceira até ajustar cento e vinte, complementados se a empresa considerasse apropriado, por serviço médico gratuito e fornecimento de medicamentos. De acordo com a legislação vigente do Ministerio de Industrias y Trabajo (Resolução no 34, de 1937), as endemias tropicais eram responsabilidade da empresa (AHA, 1940b). 
Em relação à maternidade, que recebeu um capítulo separado no regulamento, a empresa mineira acolheu as leis no 53 e 197 e os decretos regulamentários no 1632 , no 2350 e no 953 , de 1938. Conforme essa legislação, a Colômbia acolheu a recomendação da Conferência Geral da Organização Internacional do Trabalho - ocorrida em Washington, em 1919 - segundo a qual as mães tinham direito à licença remunerada de oito semanas, permanência no emprego depois da licença, quinze minutos a cada três horas para amamentar e licença de duas semanas em caso de aborto. Para evitar o aborto, estava proibido empregar mulheres grávidas em trabalhos insalubres ou perigosos, nos que demandassem grandes esforços e em trabalhos noturnos que se estendessem por mais de cinco horas, a partir das sete da noite.

A única medida de caráter preventivo era o exame médico organizado periodicamente pela administração. As iniciativas desse tipo, sem dúvida, importantes, eram só uma pequena parte do processo de configuração de um sistema de saúde para os trabalhadores. No âmbito mineiro, além do risco constante de acidente, era urgente o reconhecimento das enfermidades profissionais e auxílios por invalidez, pois o trabalho mineiro acarreta alto risco de enfermidades respiratórias e licenças por invalidez.

As soluções frente às doenças profissionais e enfermidades eram coerentes com as conquistas legislativas, mas alheias às particularidades e riscos implícitos na exploração mineira. Segundo o artigo $\mathrm{n}^{\circ} 14$, nos casos de total incapacidade, o trabalhador deveria ser licenciado do trabalho, com indenizações:

El empleado u obrero que por inhabilidad manifiesta, contraída al servicio de la Empresa como consecuencia de enfermedad o accidente, resulte incapacitado para seguir laborando en el puesto que antes desempeñaba, la compañía a su juicio y teniendo en cuenta la antigüedad y servicios prestados, podrá cambiarlo a otro puesto en donde no perjudique el trabajo, su salud no empeore, sus servicios no pongan en peligro la salud de sus compañeros de trabajo, siendo entendido que hecho el cambio, el empleado u obrero afectado percibirá el salario correspondiente al trabajo que va a desempeñar (AHA, 1940b).

Por fim, a regulamentação incluiu prestações sociais (Lei no 10, de 1934 e Decreto $n^{\circ}$ 652, de 1935). Os empregados teriam direito a um mês de férias por ano de serviço cumprido e seguro de vida equivalente a 2400 pesos para os empregados com salário anual maior de dos mil pesos e 2500 pesos para quem superasse esta cifra; para aqueles que superassem 4200 pesos, a empresa não era obrigada a garantir o seguro de vida. O seguro de vida constituía uma tênue e peculiar aposta que respondia mais ao modelo típico dos acidentes de trabalho do que às enfermidades profissionais: em caso de morte por doença profissional, a garantia do seguro se estende até seis (6) meses depois do retiro do trabalhador. Especialmente porque o que caracteriza as doenças ocupacionais e profissionais, como a silicose, é sua lenta evolução, o progressivo deterioramento do corpo ${ }^{6}$.

\section{CONSIDERAÇÕES FINAIS}

Mediante uma análise sistemática do material disponível para o período de funcionamento da EMZ (1865-1948), foram observadas as fraturas e descontinuidades nas formas de assistência médico-social. Constatou-se a materialização de vários modelos de assistência médica e social para os trabalhadores: de 1865 a 1904, caracterizado por um modelo ligado à caridade pública 
e à beneficência privada, dedicadas quase exclusivamente a enfrentar as epidemias e a pobreza, embora houvesse casos esporádicos de atendimento médico aos mineiros acidentados ou enfermos no Hospital de Caridade. Do modelo anterior, se avançou no século XX para o serviço médico da empresa mineira (1905-1912), dirigido aos trabalhadores e suas famílias. Durante esse período, Miguel María Calle, médico da EMZ, realizou seus aportes ao conhecimento da ancilostomíase e empreendeu uma importante campanha de profilaxia. Nesse segundo período, o atendimento dos trabalhadores pelo serviço médico da empresa dependeu muito do Hospital de Caridade do distrito próximo de Titiribí. Certo amálgama entre os respectivos serviços médicos do distrito e da empresa mostra que os limites entre o privado e o público eram muito mais tênues na legislação trabalhista e que a empresa não tinha assumido responsabilidades plenas quanto à saúde dos trabalhadores. Os avanços da responsabilidade privada sobre a saúde dos trabalhadores estavam em debate entre diferentes dirigentes da empresa. Um terceiro período começou com a organização do Departamento Sanitário da EMZ, em 1912, e terminou com o seu fechamento, em 1924. Esse período foi o da consolidação de um modelo empresarial de assistência para os mineiros, demarcado pela criação do hospital da empresa e pela entrada de práticas de laboratório na prática clínica e diagnóstica do serviço médico. A crise econômica da mina fez com que o Departamento Sanitário fechasse em 1924, e os trabalhadores passaram a ser atendidos novamente pelo hospital do distrito.

O fechamento definitivo da mina ocorreu em 1948. A documentação do período 1924-1948 mostrou grandes mudanças em relação à saúde e ao trabalho que colaboraram com a origem de novos modelos de saúde para os trabalhadores, baseados na legislação trabalhista nacional e na ampliação das ofertas médicas. No lugar de um serviço médico centralizado, dependente da empresa, criaram-se numerosas ofertas de produtos de saúde, lícitos e ilícitos. As empresas mineiras subcontrataram o atendimento médico aos trabalhadores e o hospital do distrito passou a ser um dos locais prioritários para tal. Além disso, no fim do quarto período (1937-1945) surgiu o movimento sindical dos mineiros, cujas reivindicações também se estendiam ao direito à saúde, representado pela exigência de assistência médica gratuita para os trabalhadores e suas famílias. As tensões entre o movimento sindical, os chefes e as autoridades locais nessa zona mineira evoluíram para o estabelecimento do Regulamento Interno da locatária El Zancudo e as petições dos trabalhadores de pequenas mineradoras, nas quais se enunciavam claramente os deveres e direitos dos trabalhadores e da empresa. Um exemplo era o respeito ao direito de cada trabalhador que ficasse doente a ser protegido e assegurado durante a enfermidade, assim como restabelecer sua saúde.

\section{NOTAS}

${ }^{1}$ Entre 1843 e 1930, por iniciativa dos sócios da EMZ após visitas à Alemanha (Freiberg) e à Inglaterra (Gales), foram contratados para trabalhar em Titiribí cerca de 40 mineiros e técnicos metalúrgicos (MOLINA e CASTAÑO, 1988, p. 115).

${ }^{2}$ Formas de contratação iguais são descritas por Georges Rosen na Inglaterra do século XIX (1943, p. 174-175). A descrição também remete às difíceis condições de trabalho, pressão e perigos descritos por Émile Zola em Germinal. Por exemplo, para aumentar o mesquinho pagamento, os mineiros reduzem os gastos de extração poupando madeira necessária para os caibros e revestimentos que suportam as fendas (ZOLA, 1986, p. 52-53).

${ }^{3}$ Em algumas regiões mineiras na Bélgica, os médicos firmavam contratos deste tipo com as empresas mineiras; tanto que, nas falas dos mineiros, os médicos eram considerados parasitas (ROSEN, 1943, p. 454).

${ }^{4}$ López foi professor de Economia Política na Escuela Nacional de Minas e também administrador da EMZ. Na Escola, ensinava, e na EMZ, aplicava os preceitos de Taylor, Fayol e Ford. Posteriormente, viajou à Inglaterra para 
GALLO, O.

aprimorar seus estudos de economia. Quando regressou à Colômbia, em 1930, se tornou o ideólogo do Partido Liberal Colombiano, propugnando um intervencionismo de Estado inspirado no keynesianismo. Sobre López, ver (MAYOR MORA., 2001).

${ }^{5} \mathrm{Na}$ Europa, a ancilostomíases ou anemia tropical era considerada uma doença ocupacional. Adquiriu uma relevância inusitada se levarmos em conta as menções em congressos internacionais: Primeiro Congresso Internacional de Mineração (1903); Congresso de Higiene e Demografia (1904); Congresso Internacional Socialista (1904); Primeiro Congresso de Doenças Profissionais (1907); Segundo Congresso de Doenças Profissionais (1914).

${ }^{6}$ Em 1941, novembro 25, o Sindicato se declarou em greve pelo anúncio de fechamento da EMZ. A justificativa da direção eram a prolongação da Guerra e os custos sociais de funcionamento. Em janeiro de 1942, com o traslado de $20 \%$ dos trabalhadores para fazendas cafeteiras e a proteção das condições de trabalho, concluiu a greve (ElTiempo, 5-6 janeiro 1942).

\section{REFERÊNCIAS}

ANALES ACADEMIA DE MEDECINA DE MEDELLÍN. Ricardo Escobar Ramos: Boceto Biográfico. Anales Academia de Medecina de Medellín (AAMM), Medellín, v. X, n. 1 y 2, p. 2 , Diciembre 1898.

ARCHIVO HISTORICO DE ANTIOQUIA (AHA). Fondo Gobierno Municipios, Municipio de Titiribí 1918; Tomo 5258, 2 de diciembre de 1912, f. 251.

ARCHIVO MUNICIPAL DE TITIRIBÍ (AMT). Varios. Informe médico oficial, janeiro de 1923.

. Alcaldía varios, Estatutos del Sindicato de mineros y Baharequeros del Zancudo de Titiribí, 7 de outubro de 1940a.

. Alcaldía varios. Reglamento de Trabajo para la Compañía Minera "Arrendataria del Zancudo", 29 de outubro de $1940 \mathrm{~b}$.

Alcaldía, papeles vários, 4 de janeiro de 1947.

BOSFORD, Robert. Zancudo mine. Titiribí. 1926.

CALLE, Miguel María. Quemaduras por el grisú y su tratamiento. AAMM, v. XIV, n. 8 y 9, p. 130-137, Agosto 1907.

1910.

Apuntes para el estudio de la anquilostomiasis. AAMM, v. XV, n. 3, p. 67-89, marzo

. Discurso. AAMM, v. I, n. 6, p. 293-298, octubre y noviembre 1949.

CALLE, Miguel María; URIBE CALAD, Lázaro. Tricocéfalos y su tratamiento con jugo de higuerón. AAMM, v. XVI, n. 6 y 7, abril 1911. 
CASTRO, Alfonso. Anquilostomiasis en Antioquia. Revista Clínica. Medellín, v. VI, n. 2023, p. 378-419, jun./1923. Estudio presentado a la Academia de Medicina de Antioquia y Caldas reunida en Medellín en octubre 1922.

COLOMBIA. Congreso de la República, 1933.

ECHEVERRI, Bernardo; URIBE, Eduardo. Condiciones generales para la explotación de minas en Colombia. Minería VIII, n. 85 y 86 (jul.-ago./1939), p. 7496-7506.

EMZ. BLAA. Empresa Minera El Zancudo. Biblioteca Luis Ángel Arango. Correspondencia. Documentos varios, 1860-1926, 27 de abril de 1867, MSS.566-136, f. 1.

GALLO, Óscar. Modelos sanitarios, prácticas médicas y movimiento sindical en la minería antioqueño. El caso de la Empresa Minera El Zancudo 1865-1950. Dissertação Mestrado. Universidade Nacional da Colômbia, Medellín. 2010.

GALLO, Óscar; MÁRQUEZ, Jorge. La silicosis o tisis de los mineros en Colombia, 1910-1960. Salud Colectiva, v. 7, n. 1, p. 35-51, Janeiro-Abril 2011 .

La enfermedad oculta: una historia de las enfermedades profesionales en Colombia, el caso de la silicosis, 1910-1950. Historia Crítica, n. 45, p. 114-143, Set./Dez. 2011 b.

GÓMEZ, Efe. La campana del conde. Boletín Clínico, v. II, n. 9, p. 372-380, fevereiro/ 1935.

GUTIÉRREZ, Rufino. Titiribí. In: GUTIERREZ, R. Monografías. Bogotá: Imprenta Nacional, 1921. Disponível em: <http://www.lablaa.org/blaavirtual/historia/uno/indice.htm>.

HERNÁNDEZ, Mario. La salud fragmentada. Bogotá: Universidad Nacional, 2002.

LÓPEZ, Alejandro. Estudios económico sobre la fundicion de minerales. Medellín. 1913a. Informe del director. dez./1913b. Ingeniería Sanitaria. Anales de Ingenieria, v. XXII, n. 261 y 262, p. 163-165, nov.. Informe primer semestre 1915. Medellín. 1915. . Informe segundo semestre 1915. Medellín. 1916. Informe segundo semestre 1916. Medellín. 1917. . Informe primer semestre 1917. Medellín. 1917. . Informe segundo semestre 1917. Medellín. 1918. . Informe primer semestre 1918. Medellín. 1919. . Informe segundo semestre 1918. Medellín. 1919. 
MAYOR MORA, Alberto. Etica, trabajo y productividad en Antioquia. Bogotá: Tercer Mundo, 1997.

MAYOR MORA. Técnica y utopía: biografía intelectual de Alejandro López (1876-1940). Medellín: Eafit, 2001.

MEJÍA, Alfonso. El obrero y el trabajo en Antioquia. Anales de la Escuela Nacional de Minas, v. II, n. 17, p. 439-457, jun. 1918.

MOLINA, Luis Fernando; CASTAÑO, Ociel. Una mina a lomo de mula: Titiribí y la Empresa Minera El Zancudo 1750-1930. Tese para obter o titulo de História. Universidade Nacional da Colômbia, Medellín. 1988.

PEREIRA GAMBA, Fortunato. Riqueza mineral de la República de Colombia. Bogotá: Imprenta de la Crónica, 1901.

POSADA, Juan de la Cruz. Silicosis (Tisis de los mineros). Minería, v. XVII, n. 100, p. 83808386, outubro 1940.

ROSEN, George. The history of miners' diseases: a medical and social interpretation. New York: Schuman's, 1943.

ZOLA, Émile. Germinal. São Paulo: Círculo do Livro, 1986. 